\title{
The integrity of crime statistics: Assessing the impact of police data bias on crime mapping
}

David Buil-Gil. University of Manchester

Angelo Moretti. Manchester Metropolitan University

Samuel H. Langton. Manchester Metropolitan University

\section{Corresponding author}

David Buil-Gil. Humanities Bridgeford Street building, School of Social Sciences, University of Manchester, 176 Oxford Road, M13 9PL, Manchester, United Kingdom.

Email: david.builgil@manchester.ac.uk

\section{Acknowledgements}

This work is supported by the Campion Grant of the Manchester Statistical Society (project title: "Mapping the bias of police records"). The authors would also like to thank Reka Solymosi for comments that greatly improved the manuscript.

\section{Abstract}

Police-recorded crimes are used by police forces to map crime patterns and design spatiallytargeted strategies. Nevertheless, maps of crimes known to police are affected by selection biases driven by unequal crime reporting rates across social groups. This paper presents a simulation study to analyse the impact of selection biases on crime maps produced at different spatial scales. Based on parameters obtained from the UK Census, we simulate a synthetic population consistent with the characteristics of Manchester. Then, based on parameters derived from the Crime Survey for England and Wales, we simulate crimes suffered by individuals, and their likelihood to be known to police. This allows comparing the relative difference between all crimes and police-recorded incidents at the different spatial scales. While the average relative difference between all crimes and those known to police is $62 \%$ across all geographical scales, the measures of dispersion of the relative difference are larger when crimes are aggregated to small geographies. The percentage of crimes unknown to police varies widely across small areas, underestimating the prevalence of crime in certain places while overestimating it in others. Micro-level crime maps are affected by a larger risk of bias than maps produced at larger scales.

\section{Keywords}

Crime analysis; Manchester; Official Statistics; Survey; Unreliability; Simulation Experiment 


\section{Introduction}

Police-recorded crimes are the main source of information used by police forces and government agencies to analyse crime patterns, investigate the geographic concentration of crime, and design and evaluate spatially-targeted policing strategies and crime prevention policies (Bowers and Johnson, 2014; Kirkpatrick, 2017; Weisburd and Lum, 2005). Police statistics are also used by criminologists to develop theories of crime and deviance (Bruinsma and Johnson, 2018). Nevertheless, crimes known to police are affected by selection biases driven by unequal crime reporting rates across social groups and geographical areas (Baumer and Lauritsen, 2010; Buil-Gil et al., 2020; Goudriaan et al., 2006; Hart and Rennison, 2003; Xie, 2014). The level of police control (e.g., police patrols, surveillance) also varies across areas, which may affect victims' willingness to report crimes to police and dictate the likelihood that police officers witness incidents in some places more than others (McCandless et al., 2016; Schnebly, 2008). The sources of measurement error that affect the bias and precision of crime statistics is an issue that merits scrutiny, since it affects policing practices, criminal justice policies and citizens' daily lives. And yet, it is an understudied issue.

The implications of crime data biases for crime mapping and policing operational decisionmaking processes are mostly unknown (Bottoms et al., 1987; Brantingham, 2018; Kirkpatrick, 2017). Moreover, police analyses and crime mapping are moving towards using increasingly fine-grained geographic units of analysis, such as street segments and micro-places containing highly homogeneous communities (Groff et al., 2010; Weisburd et al., 2009, 2012). Maps produced from offences known to police and calls for police services are used to identify the micro places where crimes are more prevalent in order to target police resources in these areas (Braga et al., 2018). In this context, we define 'micro places' as very detailed spatial units of analysis such as addresses, street segments or clusters of such units (Weisburd et al., 2009). Despite the increasing interest in small units of analysis, it remains unknown the extent to which such aggregations impact on the overall accuracy of statistical outputs and spatial analyses. In other words, it is unknown whether aggregating crime data at such detailed levels of analysis increases the impact of biases introduced by underreporting. This article presents a simulation study to analyse the impact of data biases on crime maps produced at different spatial scales. The open question that this research aims to address is whether crime maps produced at smaller, more socially homogeneous spatial scales are affected by a larger risk of bias than maps produced at larger, more socially heterogeneous geographical levels.

Since the early 1830 s, numerous researchers have expressed concern about the limitations of using official statistics to analyse crime patterns across space and time (Kitsuse and Cicourel, 1963; Maguire and McVie, 2017; Skogan, 1974; Walker, 1983). Soon after the publication of the first judiciary statistics in France, Alphonse de Candolle (1987a [1830], 1987b [1832]) cautioned that the validity of these data was likely to be affected by various sources of measurement error. For instance, crimes may not be discovered by victims, some victims may not report crimes to the authorities, offenders' identities may remain unknown, and legal procedures may not lead to conviction. Moreover, cross-sectional comparisons of the number of people convicted in court are likely to be affected by changes in prosecution activity, and the proportion of recorded crimes to unknown offences may vary across countries (Aebi and Linde, 2012; von Hofer, 2000). De Candolle (1987b [1832]) argued that the number of persons accused of crime was a better indicator of crime incidence than the number of 
persons convicted, since the former is closer to crime events in terms of legal procedure. This rationale was later used to describe the so-called 'Sellin's dictum' (i.e., "the value of a crime rate for index purposes decreases as the distance from the crime itself in terms of procedure increases", Sellin, 1931: 346), and it is the main reason why crime incidents known to the police are generally preferred over judiciary statistics when it comes to analysing crime. Policerecorded crimes, however, are also subject to criticism over the validity of recording and reporting. So much so, that such data lost the official designation of National Statistics in the UK in 2014 (UK Statistics Authority, 2014).

Perhaps the issue that raises the most concern regarding the use of police records for crime analysis and mapping is the fact that crime reporting rates are unequally distributed across social groups and geographic areas. Crime reporting to police forces is known to be more common among female victims than male victims, and young citizens report crimes less often than adults (Baumer and Lauritsen, 2010; Hart and Rennison 2003; Tarling and Morris 2010). There are also contextual factors that affect the unequal crime reporting rates across areas, such as neighbourhood economic disadvantage, the degree of urbanisation, the concentration of minorities and social cohesion (Berg et al., 2013; Goudriaan et al., 2006; Slocum et al., 2010; Xie and Lauritsen, 2012). The demographic and social characteristics of small areas are generally more homogeneous compared to larger scales (e.g., Brattbakk, 2014; Weisburd et al., 2012). Thus, crime maps produced at the level of small geographies are more likely to be affected by unequal crime reporting rates across groups than maps produced for larger, more heterogeneous spatial units. For instance, Buil-Gil et al. (2020) show that the variation in the 'dark figure of crime' (i.e., all crimes not shown in police statistics) between neighbourhoods (within cities) is greater than the variation between cities. We expect the risk of police data bias to be especially large when aggregating crime records at the level of micro places.

This paper is divided as follows: Section 2 introduces the criminology of place and the move towards low-level crime mapping in policing. Section 3 discusses the various sources of measurement error that may affect police records and introduce bias into crime maps. Section 4 introduces the data, methods and steps taken to generate the synthetic population for our simulation study, and methods used to assess the findings. Section 5 reports the results of the simulation study. Finally, Section 6 discusses the findings and presents the conclusions and limitations, along with suggestions for future research.

\section{The criminology of place}

In the 1980s, several researchers began analysing the concentration of crime in places, and found that a large proportion of crimes known to the police concentrated in a small number of micro places. Pierce et al. (1988) showed that $50 \%$ of all calls for police services in Boston took place in just $2.6 \%$ of addresses, suggesting that a disproportionately large volume of total crime could be attributed to just a handful of places. A year later, Sherman et al. (1989) conducted similar research in Minneapolis, obtaining almost the same results: $2.5 \%$ of addresses in this city generated $50 \%$ of all crime calls to the police. These were only two of the first studies looking into the concentration of crime in places. Since then, many other researchers have published remarkably similar findings (see a review in Lee et al., 2017). Environmental criminologists argue that the social and contextual conditions that favour crime 
vary across micro places, and that opportunities for crime are structured within very small geographic areas (Brantingham and Brantingham, 1995; Weisburd et al., 2012).

Given the persistency of this finding across multiple study sites and countries, Weisburd (2015) argues for a so-called 'law of crime concentration' at micro places, namely, that "for a defined measure of crime at a specific microgeographic unit, the concentration of crime will fall within a narrow bandwidth of percentages for a defined cumulative proportion of crime" ( $p$. 138). This has served as a basis for police forces all over the world to develop place-based strategies that increase police control over those areas where crime is highly concentrated to efficiently reduce citywide crime (Braga et al., 2018; Groff et al., 2010; Kirkpatrick, 2017).

However, the vast majority of research analysing crime concentration, and evaluating the impact of place-based policing interventions, is based on data about crimes known to the police. For instance, 41 out of 44 studies examining the crime concentration at places reviewed by Lee et al. (2017) used crime incidents reported to police, and 4 out of 44 analysed calls for police services (note that some studies used more than one source of data). Both these sources of data depend on citizens' willingness to report crimes and cooperate with the police, which are known to be affected by the social and demographic characteristics of individuals, but also by variables that operate at the scales of small communities, such as concentrated disadvantage, perceived disorder and collective efficacy (Jackson et al., 2013). Weisburd et al. (2012: 5) argue that "the criminology of place [...] emphasizes the importance of micro units of geography as social systems relevant to the crime problem". And yet, these micro-level social systems may also be key in explaining why crime reporting rates - and the likelihood of crimes being known to police - are larger in some places than others, and as such, we might expect that the sources of measurement error that affect police data will vary across micro places.

\section{Crime mapping and data bias}

There are four primary sources of data bias that may affect the accuracy of crime maps produced solely from police records. First, the willingness of residents to report crimes to police is known to be associated with individual and contextual factors that vary across geographic areas (Hart and Rennison, 2003). There are demographic, social, economic and environmental factors that affect crime reporting rates. For example, the victims' sex, age, employment status, education level and ethnic group are all good predictors of their likelihood to report crimes to the police (Hart and Rennison, 2003). Since some of these resident characteristics concentrate in particular areas, we also expect crime reporting rates to vary across areas. Generally, deprived neighbourhoods have lower crime reporting rates than middle-class areas (Baumer and Lauritsen, 2010; Goudriaan et al., 2006), and crimes that take place in cohesive areas have a higher chance of being known to the police (Goudriaan et al., 2006; Jackson et al., 2013). Moreover, residents from rural areas are generally more willing to cooperate with police services than urban citizens (Hart and Rennison 2003).

Second, various papers have found that the overall crime rate and citizens' perceptions about police forces, which also vary across areas, affect residents' willingness to cooperate with the police (e.g., Xie 2014). Berg et al. (2013) show that the most important contextual factor in explaining crime reporting is the level of crime in the area. Jackson et al. (2013) argue that the 
level of trust in police fairness and residents' perceptions of police legitimacy are key to predict the willingness to cooperate with police forces.

Third, unequal police control across areas may inflate crime statistics in some places but not others. Schnebly (2008) shows that cities with more police officers trained in communityoriented policing generally have higher rates of police notification, whereas McCandless et al. (2016) argue that poorly handed stop and search practices may discourage residents from engaging with the police.

Fourth, there may be differences between counting rules applied by different police forces (Aebi and Linde, 2012; von Hofer, 2000). This is not expected to be a major source of error in England and Wales, since all 43 police forces follow common counting rules (National Crime Recording Standards and Home Office Counting Rules for Recorded Crime). Nevertheless, we note that in 2014, Her Majesty's Inspectorate of Constabulary and Fire \& Rescue Services conducted an inspection about police statistics and concluded that certain counting practices are unequally followed across police forces (HMIC, 2014).

Some of these sources of measurement error were mentioned by Skogan (1977: 41) to argue that the dark figure of crime "limits the deterrent capability of the criminal justice system, contributes to the misallocation of police resources, renders victims ineligible for public and private benefits, affects insurance costs, and helps shape the police role in society". Moreover, the UK public administration also acknowledges that "there is accumulating evidence that suggests the underlying data on crimes recorded by the police may not be reliable" (UK Statistics Authority, 2014: 2). As a consequence, in 2014 crime data were removed from the UK National Statistics designation.

Given that many of the factors generating disparities in the bias and precision of policerecorded crime data are non-uniformly distributed across space, it is plausible that the bias affecting crime data is also larger in certain places than in others (Buil-Gil et al., 2020). For example, the difference between crimes known to police and all crimes is likely to be much larger in urban areas characterised by economic deprivation, large proportions of students and young citizens, high crime levels, large proportions of minorities and low levels of social cohesion, compared to ageing, middle-class, rural areas with a majority of white citizens. This paper assesses whether micro-level maps of crimes known to police are affected by a larger risk of bias than maps produced at larger spatial scales. Oberwittler and Wikström (2009: 41) argue that, in order to analyse crime, "smaller geographical units are more homogeneous, and hence more accurately measure environments. In other words, smaller is better". Smaller units of analysis are said to be better for explaining criminal behaviour since crime is determined by opportunities that occur in the immediate environment. However, smaller units of analysis may also be better for explaining the amount of crime which remains hidden in police statistics (either because victims and witnesses fail to report or because the police fails to record). The 'aggregation bias', which argues that what is true for a group should also be true for individuals within such a group, tends to be used to justify the selection of smaller units of spatial analysis in crime mapping. It would be paradoxical and self-defeating if, in seeking to avoid aggregation bias with the use of micro-scale units, studies increase the risk of maps being affected by selection biases. This would have significant repercussions for academic endeavour and policing practices. 


\section{Data and methods}

Simulation studies are computer experiments in which data is created via pseudo-random sampling in order to evaluate the bias and variance of estimators, compare estimators, investigate the impact of sample sizes on estimators' performance, and select optimal sample sizes, among others (Moretti, 2020). Brantingham and Brantingham (2004) recommend the use of computer simulations to understand crime patterns and provide policy guidance for crime control. In this study, we generate a synthetic dataset of crimes known and unknown to police in Manchester, UK, and aggregate crimes at different spatial scales. This permits an investigation into whether maps produced from crimes known to police at the micro-scale level suffer from a higher risk of bias compared to those at larger aggregations, such as neighbourhoods and wards.

Based on parameters obtained from the 2011 UK Census, we simulate a synthetic individuallevel population consistent with the characteristics of Manchester. The simulated population reflects the real distributions and parameters of variables related to individuals residing in each area of the city (i.e., mean, proportion, and variance of the citizens' age, sex, employment status, education level and ethnicity). Then, based on parameters derived from the Crime Survey for England and Wales (CSEW) 2011/12, we simulate the victimisation of these individuals across social groups and areas, and predict the likelihood of these crimes being known to the police. This allows us to compare the relative difference between all crimes and police-recorded incidents at the different spatial scales. The main motivation for using a simulation study with synthetic data, instead of simply using crime records, is because the absolute number of crimes in places is an unknown figure, regardless which source of data we use (see Section 3). Police records are affected by a diverse array of sources of error which vary between areas, and the CSEW sample is only designed to allow the production of reliable estimates at the level of Police Force Areas (smaller areas are unplanned domains with very small sample sizes where analyses based on direct estimates lead to unreliable outputs; Buil-Gil et al., 2020).

In this section, we describe the data and methods used to generate the synthetic population of crimes known and unknown to police and evaluate the difference between those at the different scales. Section 4.1 outlines the generating mechanism of the population and the steps of our simulation study. In Section 4.2, the empirical evaluation of the simulated dataset of crimes is presented. We discuss methods to assess the results in Section 4.3.

\subsection{Generating the population and simulation steps}

The simulation of our synthetic population involves four steps which are described in detail below. All analyses have been programmed in R ( $R$ Core Team, 2020) and all data and code used for this simulation study are available from a public Github repository (see anonymised repository: https://anonymous.4open.science/r/25e50893-ff70-4a16-b7b2-a58fa469b9c7/).

\section{Step 1. Simulating a synthetic population from Census data}

The first step is to generate a synthetic population consistent with the social, demographic and spatial characteristics of Manchester. We download aggregated data about residents at the Output Area (OA) level from the Nomis website (https://www.nomisweb.co.uk/census/2011), 
which publishes data recorded by the UK Census 2011. For consistency, we will conduct all our analyses using information collected in 2011. From Nomis we obtain empirical parameters of various variables in each $\mathrm{OA}$ in Manchester. Census data achieves nearly complete coverage of the population, and therefore the sources of error that may arise from using these data are almost non-existent. OAs are the smallest geographic units for which census data are openly published in the UK. The minimum population size per OA is 40 households and 100 residents, but the average size is 125 households. We will also use other units of geography in further steps: Lower Layer Super Output Areas (LSOAs), that generally contain between four and six OAs with an average population size of 1,500; Middle Layer Super Output Areas (MSOAs), which have an average population size of 7,200. The largest scale used is wards. In Manchester local authority there are 1,530 OAs, 282 LSOAs, 57 MSOAs and 32 wards.

From the Census, we obtain the number of citizens living in each OA (i.e., resident population size), the mean and standard deviation of age by OA, and the proportion of citizens in each area with the following characteristics defined by binary variables (in parentheses, we detail the reference category): sex (male), ethnicity (white), employment status (population without any income), education (higher education or more). We use this information to simulate our synthetic individual-level population and their corresponding social-demographic characteristics within each OA. This allows us, in subsequent steps, to simulate crimes experienced by citizens, as well as the likelihood of each crime being known to the police, based on parameters obtained from survey data. We use these specific variables since these are known to be associated with crime victimisation and crime reporting rates (see Section 3). Thus, the selection of Census parameters is driven by the literature review and the availability of data recorded by the Census.

The variables are generated for $d=1, \ldots, D$ OAs and $i=1, \ldots, N_{d}$ individual citizens according to the distributions detailed below, where $N_{d}$ denotes the population dimension in the $d^{\text {th }} \mathrm{OA}$ :

- $A g e_{d i} \sim N\left(\mu_{d}^{A g e}, \sigma_{d}^{2, A g e}\right)$, where $\mu_{d}^{A g e}$ and $\sigma_{d}^{2, A g e}$ denote the mean and variance of age for the $d^{\text {th }} \mathrm{OA}$.

- $\quad$ Sex $x_{d i} \sim \operatorname{Bernoulli}\left(\pi_{d}^{\text {Male }}\right)$, where $\pi_{d}^{\text {Male }}$ denotes the proportion of males in $d^{\text {th }}$ OA.

- NoInc $d i \sim$ Bernoulli $\left(\pi_{d}^{\text {NoInc }}\right)$, where $\pi_{d}^{\text {NoInc }}$ denotes the proportion of citizens without any income in the $d^{\text {th }} \mathrm{OA}$.

- $H E_{d i} \sim \operatorname{Bernoulli}\left(\pi_{d}^{H E}\right)$, where $\pi_{d}^{H E}$ denotes the proportion of citizens with high education (holding a university degree) in the $d^{\text {th }} \mathrm{OA}$.

- White di $\sim$ Bernoulli $\left(\pi_{d}^{\text {White }}\right)$, where $\pi_{d}^{\text {White }}$ denotes the proportion of white citizens in the $d^{\text {th }} \mathrm{OA}$.

Thus, we generate $\mathrm{N}=503,127$ individuals with their individual characteristics across $\mathrm{D}=1,530$ OAs in Manchester. Given that we simulate all individual information based on population parameters obtained from the Census using small spatial units of analysis (i.e., OAs), our synthetic population is very similar (in terms of distributions and ranking) to the empirical population of each OA. The Spearman's rank correlation coefficient of the mean of age, sex, 
income, higher education and ethnicity across areas in Census data and our simulated dataset is almost perfect (i.e., larger than 0.99 for all variables).

\section{Step 2. Simulating crime victimisation from CSEW data}

We use parameters obtained from the CSEW 2011/12 to generate the crimes experienced by each individual citizen. The CSEW is an annual victimisation survey conducted in England and Wales. Its sampling design consists of a multi-stage stratified random sample by which a randomly selected adult (aged 16 or more) from a randomly selected household is asked about experienced victimisation in the last 12 months (Office for National Statistics, 2013). The survey also includes questions about crime reporting to the police and whether each crime took place in the local area, amongst others. The main part of the survey is completed faceto-face in respondents' households, although some questions (about drugs and alcohol use, and domestic abuse) are administered via computer-assisted personal interviewing. The CSEW sample size in 2011/12 was 46,031 respondents.

In order to simulate the number of crimes faced by each individual unit within our synthetic population of Manchester residents, we first estimate Negative Binomial regression models of crime victimisation from CSEW data, and then use the model parameter estimates to predict crime incidence within our simulated population. Given that different crime types are known to be associated with different social and contextual variables (Andresen and Linning, 2012), and the variables associated with crime reporting to the police also vary according to crime type (Hart and Rennison, 2003; Tarling and Morris, 2010), we estimate one Negative Binomial regression model by each of four groups of crime types:

- Vehicle crimes: includes the number of (a) thefts of motor vehicles, (b) things stolen off vehicles, and (c) vehicles tampered or damaged, all during the last 12 months.

- Residence crimes: number of times (a) someone entered a residence without permission to steal, (b) someone entered a residence without permission to cause damage, (c) someone tried to enter a residence without permission to steal or cause damage, (d) anything got stolen from a residence, (e) anything stolen from outside a residence (garden, doorstep, garage), and (f) anything damaged outside a residence. These refer to events happening both at the current and previous households during the last 12 months.

- Theft and property crimes (excluding burglary): number of times (a) something stolen out of hands, pockets, bags or cases, (b) someone tried to steal something out of hands, pockets, bags or cases, (c) something stolen from a cloakroom, office, car or anywhere else, and (d) bicycle stolen, all during the last 12 months.

- Violent crimes: number of times (a) someone deliberately hit the person with fists or weapon or used force or violence in any way, (b) someone threatened to damage or use violence on the person or things belonging to the person, (c) someone sexually assaulted or attacked the person, (d) some member of the household hit or used weapon, or kicked, or used force in any way on the person, all during the last 12 months.

The Negative Binomial regression model is a widely adopted model in this context, which has been proven to adjust well to the skewness of crime count variables (Britt et al., 2018; Chaiken and Rolph, 1981). In order to estimate the Negative Binomial regression models, we use the same independent variables described in Step 1 (i.e., age, sex, employment status, education 
level and ethnic group). However, in this step these are taken from the CSEW. This allows us to obtain the regression model coefficient estimates and dispersion parameter estimates (Table 1), denoted by $\widehat{\alpha}_{p}$ for a generic $p$ independent variable and $\widehat{\theta}$, respectively, that will be used to generate the crime counts per person in the synthetic population.

Table 1. Negative Binomial Generalised Linear models of crime victimisation estimated from CSEW 2011/12 data.

\begin{tabular}{|c|c|c|c|c|}
\hline & $\begin{array}{l}\text { Vehicle } \\
\text { crimes }\end{array}$ & $\begin{array}{l}\text { Residence } \\
\text { crimes }\end{array}$ & $\begin{array}{l}\text { Theft and } \\
\text { property crimes }\end{array}$ & Violent crimes \\
\hline (Intercept) & $-0.967^{\star * *}$ & $-0.926^{* * *}$ & $-1.594^{* * *}$ & $0.439^{* *}$ \\
\hline Age & $-0.017^{* * *}$ & $-0.011^{* * *}$ & $-0.028^{* * *}$ & $-0.046^{* * *}$ \\
\hline Male $(0 / 1)$ & $0.125^{\star *}$ & 0.027 & $0.210^{* * *}$ & 0.002 \\
\hline White $(0 / 1)$ & $-0.140^{\star}$ & $-0.203^{* *}$ & 0.015 & $0.241^{+}$ \\
\hline No income $(0 / 1)$ & $-0.426^{* * *}$ & $0.215^{\star * *}$ & -0.048 & $-0.301^{* * *}$ \\
\hline High education $(0 / 1)$ & 0.036 & $-0.165^{\star * *}$ & $0.116^{*}$ & $-0.133^{+}$ \\
\hline Nagelkerke's Pseudo- $R^{2}$ & 0.27 & 0.33 & 0.24 & 0.24 \\
\hline AIC & 28344 & 30422 & 16598 & 22132 \\
\hline
\end{tabular}

${ }^{* * *} p$-value $<0.001,{ }^{* *} p$-value $<0.01,{ }^{*} p$-value $<0.05,{ }^{+} p$-value $<0.1$

Table 1 shows the Negative Binomial regression models used to estimate crime victimisation from CSEW 2011/12 data. We utilise these regression coefficients to generate our synthetic population of crimes, but these also provide some information about which individual characteristics are associated with more or less risk of victimisation by crime type. For example, age is negatively associated with crime victimisation in all crime types. Being male is a good predictor of suffering vehicle and property crimes, but not residence or violent crimes. Being white is associated with a higher risk of suffering violent crime, whereas non-whites have a higher risk of suffering vehicle and residence crimes. With regards to income levels, those with some type of income have a higher risk of victimisation by vehicle and violent crimes, whereas respondents without any income have a higher risk of suffering residence crimes. Finally, citizens with a higher education degree generally suffer more property crimes than residents without university qualifications, whereas those without higher education certificates are at a higher risk of suffering residence and violent crimes.

Crime victimisation counts for each unit in the simulated population are generated following a Negative Binomial regression model using the regression coefficient and dispersion parameter estimates obtained from the CSEW (Table 1) and the independent variables simulated in Step 1. For example, we predict the number of vehicle crimes $\left(V e h i_{i}\right)$ suffered by a given individual $i$ as follows:

$$
V e h i_{i} \sim N B\left(\hat{\tau}_{i}^{V e h i}, \widehat{\theta}^{V e h i}\right),
$$

where $N B$ denotes the Negative Binomial distribution, and:

$$
\begin{gathered}
\widehat{\tau}_{i}^{\text {Vehi }}=\widehat{\alpha}_{0}^{\text {Vehi }}+\widehat{\alpha}_{1}^{\text {Vehi }} \mathrm{Age}_{i}+\widehat{\alpha}_{2}^{\text {Vehi }} \operatorname{Sex}_{i}+\widehat{\alpha}_{3}^{\text {Vehi }} \text { White }_{i}+, \widehat{\alpha}_{4}^{\text {Vehi }} \mathrm{NoInc}_{i}+\text { Eq. } 2 \\
\widehat{\alpha}_{5}^{\text {Vehi }} H E_{i}, i=1, \ldots, N .
\end{gathered}
$$

We repeat this procedure for all four crime types. Thus, the variability and relationships between variables observed in the CSEW are reproduced in our simulated population, and we assume that these values represent the true extent of crime victimisation in the population of Manchester. 


\section{Step 3. Simulating crimes known to police from CSEW data}

The third step consists of estimating whether each simulated crime is known to the police or not. This allows us to analyse the difference between all crimes (generated in Step 2), and those crimes known to the police (to be estimated in Step 3) for each area in Manchester. First, we create a new dataset in which every crime generated in Step 2 becomes the observational unit. Here, our units of analysis are crimes in places, instead of individual citizens, therefore some residents may be represented more than once (i.e., those who suffered multiple forms of victimisation).

In order to estimate the likelihood of each crime being known to the police, we follow a similar procedure as in Step 2, but in this case we make use of logistic regression models for binary outcomes, which are better described by the Bernoulli distribution of crime reporting. First, we estimate a logistic regression model of whether crimes are known to police or not. We use the CSEW dataset of crimes ( $n=14,758$ ), and fit the model using the same independent variables as in Step 2 to estimate the likelihood of crimes being known to the police (see the results of logistic regression models in Table 2).

Table 2. Logistic models of crimes known to police estimated from CSEW 2011/12 data.

\begin{tabular}{|c|c|c|c|c|}
\hline & $\begin{array}{l}\text { Vehicle } \\
\text { crimes }\end{array}$ & $\begin{array}{l}\text { Residence } \\
\text { crimes }\end{array}$ & $\begin{array}{l}\text { Theft and } \\
\text { property crimes }\end{array}$ & Violent crimes \\
\hline (Intercept) & $-0.467^{\star \star}$ & $-0.808^{\star * \star}$ & $-0.774^{\star \star \star}$ & 0.242 \\
\hline Age & -0.003 & 0.001 & $0.006^{*}$ & 0.003 \\
\hline Male $(0 / 1)$ & $-0.122^{+}$ & 0.094 & $-0.160^{+}$ & $-0.259^{\star *}$ \\
\hline White $(0 / 1)$ & 0.070 & 0.127 & 0.103 & -0.034 \\
\hline No income $(0 / 1)$ & $-0.152+$ & $0.189^{* *}$ & -0.156 & 0.026 \\
\hline High education ( $0 / 1)$ & 0.002 & 0.044 & $0.297^{* *}$ & $-0.190^{*}$ \\
\hline $\begin{array}{l}\text { Nagelkerke's Pseudo- } R^{2} \\
\text { AIC }\end{array}$ & $\begin{array}{c}0.25 \\
4946.8\end{array}$ & $\begin{array}{c}0.38 \\
5105.3\end{array}$ & $\begin{array}{c}0.29 \\
2622.5\end{array}$ & $\begin{array}{c}0.25 \\
3163.1\end{array}$ \\
\hline
\end{tabular}

${ }^{* * *} p$-value $<0.001,{ }^{* *} p$-value $<0.01,{ }^{*} p$-value $<0.05,{ }^{+} p$-value $<0.1$

Second, we estimate whether each crime in our simulated dataset is known to the police following a Bernoulli distribution from the regression coefficient estimates shown in Table 2 and the independent variables simulated in Step 1. As in the previous case, we repeat this procedure for each crime type, since some variables may affect some crime types in a different way than others (Baumer and Lauritsen, 2010). For example, to estimate whether each vehicle crime $j$, suffered by an individual $i$, is known to police $\left(K V e h i_{j i}\right)$ we calculate:

$$
\text { KVehi } i_{j i} \sim \operatorname{Bernoulli}\left(\exp \left(\hat{p}_{j i}{ }^{K V e h i}\right) /\left[1+\exp \left(\hat{p}_{j i}{ }^{K V e h i}\right)\right]\right),
$$

where:

$$
\begin{aligned}
& \hat{p}_{j i}{ }^{K V e h i}=\widehat{\gamma}_{0}{ }^{\text {KVehi }}+\widehat{\gamma}_{1}{ }^{K V e h i} A g e_{j i}+\widehat{\gamma}_{2}{ }^{K V e h i} \operatorname{Sex}_{j i}+\widehat{\gamma}_{3}{ }^{K V e h i} \text { White }_{j i}+\text { Eq. } 4 \\
& \widehat{\gamma}_{4}{ }^{K V e h i}{ }^{N o I n c} c_{j i}+\widehat{\gamma}_{5}{ }^{K V e h i} H E_{j i}, j=1, \ldots, J \text {. }
\end{aligned}
$$

$\hat{\gamma}_{p}$ denotes the regression model coefficient estimate for a $p$ independent variable and $J$ denotes all simulated crimes. 


\section{Step 4. Simulating whether crimes occur in the local area from CSEW data}

One important constraint of crime estimates produced from the CSEW is that these provide information about area victimisation rates (i.e., number of crimes suffered by citizens living in one area, regardless of where crimes took place), instead of area offence rates (i.e., number of crimes taking place in each area). This may complicate efforts to compare and combine survey-based estimates with police records. Given that our simulated dataset of crimes is based on CSEW parameters and Census data about residential population characteristics, our synthetic dataset of crimes is also likely to be affected by this limitation. In order to mitigate the impact of this shortcoming on any results drawn from our study, we estimate whether each crime took place in the residents' local area or somewhere else, and remove from the study all those crimes that do not take place within 15 minutes walking distance from the citizens' household. This may facilitate efforts to compare our simulated dataset of crimes with policerecorded incidents, but we note that our synthetic dataset does not account for those crimes that take place in an area but are suffered by persons living in any other place. According to estimates drawn from the CSEW 2011/12, this represents $26.0 \%$ of all crimes, which are likely to be overrepresented in commercial areas and business districts in the city centre, where the difference between the workday population and the number of residents is generally very large (e.g., 490.2\% in Manchester city centre; Manchester City Council, 2011). We return to this point in the discussion section to discuss ways in which this shortcoming may be further addressed in future research.

In order to estimate whether each crime took place in the victims' local area or somewhere else, we follow the same procedure as in Step 3. First, we estimate a logistic regression model of crimes happening in the local area (as opposed to crimes happening anywhere else) from the CSEW dataset of crimes. We use the same individual independent variables as above (see model results in Table 3). Second, we estimate whether each simulated crime took place in the resident's local area or somewhere else following a Bernoulli distribution from the regression coefficient estimates presented in Table 3 and the independent variables simulated in Step 1. For example, to estimate whether vehicle crime $j$ suffered by person $i$ took place in local area, denoted by $A V e h i_{j i}$, we compute:

$$
\text { AVehi } i_{j i} \sim \text { Bernoulli }\left(\exp \left(\hat{p}_{j i}{ }^{A V e h i}\right) /\left[1+\exp \left(\hat{p}_{j i}{ }^{A V e h i}\right)\right]\right), \quad \text { Eq. } 5
$$

where:

$$
\begin{gathered}
\hat{p}_{j i}{ }^{\text {AVehi }}=\widehat{\beta}_{0}{ }^{A V e h i}+\hat{\beta}_{1}^{A V e h i}{ }^{A g e_{j i}}+\hat{\beta}_{2}^{A V e h i} \operatorname{Sex}_{j i}+\hat{\beta}_{3}^{A V e h i} \text { White }_{j i}+ \\
\hat{\beta}_{4}^{A V e h i} \operatorname{NoInc}_{j i}+\hat{\beta}_{5}^{A V e h i} H E_{j i}, j=1, \ldots J
\end{gathered}
$$

where $\hat{\beta}_{p}$ is the regression model coefficient estimate for a $p$ independent variable. 
Table 3. Logistic models of crimes taking place in the local area estimated from CSEW $2011 / 12$ data.

\begin{tabular}{|c|c|c|c|c|}
\hline & $\begin{array}{l}\text { Vehicle } \\
\text { crimes }\end{array}$ & $\begin{array}{l}\text { Residence } \\
\text { crimes }\end{array}$ & $\begin{array}{l}\text { Theft and } \\
\text { property crimes }\end{array}$ & Violent crimes \\
\hline (Intercept) & $1.763^{* * *}$ & $1.308^{* * *}$ & $0.327^{+}$ & 0.029 \\
\hline Age & -0.001 & $0.041^{* * *}$ & -0.004 & $0.012^{* \star \star}$ \\
\hline Male $(0 / 1)$ & $-0.143^{+}$ & -0.146 & -0.149 & $-0.396^{\star \star *}$ \\
\hline White $(0 / 1)$ & $-0.478^{* * *}$ & 0.050 & -0.136 & 0.028 \\
\hline No income $(0 / 1)$ & 0.104 & $-0.258^{+}$ & 0.128 & $0.533^{\star \star \star}$ \\
\hline High education $(0 / 1)$ & $-0.242^{* *}$ & $-0.466^{\star * *}$ & $-0.404^{* * *}$ & -0.388 \\
\hline Nagelkerke's Pseudo-R² & 0.21 & 0.27 & 0.30 & 0.26 \\
\hline AIC & 4220.7 & 1857.7 & 2687.5 & 3128.9 \\
\hline
\end{tabular}

${ }^{\star \star *} p$-value $<0.001,{ }^{* *} p$-value $<0.01,{ }^{*} p$-value $<0.05,{ }^{+} p$-value $<0.1$

Then, we remove from our synthetic dataset of crimes all those offences that did not take place in the local area. Our final sample size is 359,248 crimes distributed across 1,530 OAs in Manchester.

\subsection{Empirical evaluation of simulated dataset of crimes}

Once all synthetic data are generated, we use victimisation data recorded by the CSEW and data about crimes known to Greater Manchester Police (GMP) in order to empirically evaluate whether our simulated dataset of crimes match the empirical values of crime.

First, Table 4 compares the average number of crimes suffered by individuals across sociodemographic groups as recorded by the CSEW 2011/12 and our simulated dataset. The distribution of the synthetic dataset of crimes is very similar to that of the CSEW for vehicle crimes, residence crimes and property crimes, but values appear to be slightly larger in the synthetic population than in the survey data. For instance, citizens younger than 35 suffer the most crimes in both datasets, and males suffer more vehicle, residence and property crimes but not violent crimes. Crime victimisation differences by ethnicity, employment status and education level shown in the CSEW are also observed in the simulated dataset of crimes. In the case of violent crimes, incidences in our simulated population appear to be notably higher than those observed in the CSEW. We note that our simulated dataset refers to crimes taking place in Manchester local authority, whereas the CSEW reports data for all England and Wales. In 2011/12, the overall rate of violent crimes known to police per 1,000 citizens was $54.7 \%$ larger in Manchester than in the rest of England and Wales (Office for National Statistics, 2019), and the Crime Severity Score for 2011/12 (an index that ranks the severity of crimes in each local authority, giving more weight to violent crimes than other crime types) was 104.6\% larger in Manchester than the average of England and Wales (Office for National Statistics, 2020). Therefore, the differences observed between CSEW and our synthetic population of crimes are likely to reflect true variations between the crime levels in Manchester and England and Wales as a whole. Our simulated dataset of violent crimes reflects the differences in crime victimisation observed in the CSEW in terms of age, gender and other demographic characteristics. 
Table 4. Average number of crimes suffered by individuals by social and demographic characteristics in CSEW (weighted) and our simulated data.

\begin{tabular}{|c|c|c|c|c|c|c|c|c|}
\hline & \multicolumn{2}{|c|}{ Vehicle crimes } & \multicolumn{2}{|c|}{ Residence crimes } & \multicolumn{2}{|c|}{ Property crimes } & \multicolumn{2}{|c|}{ Violent crimes } \\
\hline & CSEW & Simulation & CSEW & Simulation & CSEW & Simulation & CSEW & Simulation \\
\hline $\begin{array}{l}16 \text { to } 35 \\
\text { years }\end{array}$ & 0.19 & 0.19 & 0.23 & 0.28 & 0.12 & 0.11 & 0.38 & 0.48 \\
\hline $\begin{array}{l}36 \text { to } 55 \\
\text { years }\end{array}$ & 0.18 & 0.14 & 0.21 & 0.23 & 0.07 & 0.07 & 0.25 & 0.21 \\
\hline $56+$ years & 0.09 & 0.10 & 0.15 & 0.17 & 0.03 & 0.04 & 0.04 & 0.08 \\
\hline Male & 0.17 & 0.20 & 0.20 & 0.27 & 0.08 & 0.12 & 0.22 & 0.52 \\
\hline Female & 0.14 & 0.17 & 0.19 & 0.26 & 0.07 & 0.10 & 0.23 & 0.55 \\
\hline White & 0.15 & 0.18 & 0.19 & 0.24 & 0.07 & 0.11 & 0.22 & 0.57 \\
\hline $\begin{array}{l}\text { Other than } \\
\text { white }\end{array}$ & 0.18 & 0.20 & 0.27 & 0.31 & 0.09 & 0.11 & 0.25 & 0.46 \\
\hline $\begin{array}{l}\text { Not } \\
\text { working }\end{array}$ & 0.10 & 0.15 & 0.20 & 0.30 & 0.06 & 0.11 & 0.19 & 0.47 \\
\hline Working & 0.19 & 0.22 & 0.20 & 0.23 & 0.08 & 0.11 & 0.25 & 0.59 \\
\hline $\begin{array}{l}\text { High } \\
\text { education }\end{array}$ & 0.17 & 0.19 & 0.20 & 0.23 & 0.09 & 0.12 & 0.21 & 0.47 \\
\hline $\begin{array}{l}\text { No high } \\
\text { education }\end{array}$ & 0.16 & 0.18 & 0.22 & 0.28 & 0.08 & 0.11 & 0.25 & 0.56 \\
\hline
\end{tabular}

Second, Table 5 presents the proportion of crimes that are known to the police grouped by the socio-demographic characteristics of victims in CSEW and our simulated data. By looking at the table, we see that the proportions related to the CSEW are very similar to the ones obtained on the simulated data. This shows that modelling results are consistent, thus preserving relationships between variables.

Table 5. Proportion of crimes known to police by social and demographic characteristics of victims in CSEW (weighted) and our simulated data.

\begin{tabular}{|c|c|c|c|c|c|c|c|c|}
\hline & \multicolumn{2}{|c|}{ Vehicle crimes } & \multicolumn{2}{|c|}{ Residence crimes } & \multicolumn{2}{|c|}{ Property crimes } & \multicolumn{2}{|c|}{ Violent crimes } \\
\hline & CSEW & Simulation & CSEW & Simulation & CSEW & Simulation & CSEW & Simulation \\
\hline $\begin{array}{l}16 \text { to } 35 \\
\text { years }\end{array}$ & 0.36 & 0.35 & 0.37 & 0.37 & 0.35 & 0.34 & 0.39 & 0.42 \\
\hline $\begin{array}{l}36 \text { to } 55 \\
\text { years }\end{array}$ & 0.32 & 0.33 & 0.41 & 0.38 & 0.43 & 0.38 & 0.44 & 0.43 \\
\hline $56+$ years & 0.36 & 0.32 & 0.40 & 0.38 & 0.41 & 0.41 & 0.43 & 0.44 \\
\hline Male & 0.34 & 0.33 & 0.40 & 0.39 & 0.36 & 0.33 & 0.39 & 0.38 \\
\hline Female & 0.35 & 0.36 & 0.39 & 0.36 & 0.41 & 0.37 & 0.44 & 0.44 \\
\hline White & 0.35 & 0.35 & 0.39 & 0.38 & 0.39 & 0.35 & 0.41 & 0.41 \\
\hline $\begin{array}{l}\text { Other than } \\
\text { white }\end{array}$ & 0.34 & 0.34 & 0.42 & 0.36 & 0.35 & 0.33 & 0.39 & 0.42 \\
\hline $\begin{array}{l}\text { Not } \\
\text { working }\end{array}$ & 0.34 & 0.33 & 0.43 & 0.39 & 0.37 & 0.32 & 0.44 & 0.41 \\
\hline Working & 0.35 & 0.36 & 0.36 & 0.35 & 0.39 & 0.37 & 0.39 & 0.41 \\
\hline $\begin{array}{l}\text { High } \\
\text { education }\end{array}$ & 0.34 & 0.35 & 0.38 & 0.38 & 0.43 & 0.40 & 0.37 & 0.38 \\
\hline $\begin{array}{l}\text { No high } \\
\text { education }\end{array}$ & 0.33 & 0.35 & 0.37 & 0.37 & 0.35 & 0.33 & 0.41 & 0.42 \\
\hline
\end{tabular}

Third, we download crime data recorded by GMP (https://data.police.uk/) and compare arealevel aggregates of crimes known to GMP with our synthetic dataset of crimes known to the police. To do this, we only consider those simulated crimes that were estimated as being known to police and taking place in the local area. Spearman's rank correlation and Global Moran's I coefficients between the area-level aggregates of our synthetic dataset of crimes 
and crimes known to GMP are reported in Table 6. Tiefelsdorf's (2000) exact approximation of the Global Moran's I test is used as a measure of spatial dependency between the two measures, to analyse if the number of crimes in our simulated dataset is explained by the value of crimes known to GMP in surrounding areas (Bivand et al., 2009).

We aggregate all crimes known to police to each spatial unit using the 'sf' package in $\mathrm{R}$ (Pebesma, 2018). Out of the 87,457 crimes known to GMP, 642 could not be geocoded. We note that we obtained slightly different results using two different analytical approaches to aggregating crimes in areas (i.e., counting crimes in OAs and then aggregating from OAs to LSOA, MSOAs and wards using a lookup table, versus counting crimes in OAs, LSOAs, MSOAs and wards respectively), which may be due to errors arising from the aggregation process or inconsistencies in the lookup table. We chose the second approach (i.e., counting points in polygons at the different scales), since, on average, a larger number of offences were registered in each area using this method. Tompson et al. (2015) demonstrate that open crime data published in England and Wales is spatially precise at the levels of LSOA and MSOA, but the spatial noise added to these data for the purposes of anonymity means that OA-level maps have inadequate precision. Thus, we only present and discuss the results obtained at LSOA and larger spatial levels.

Table 6. Measures of correlation between simulated dataset of crimes known to police and incidents recorded by Greater Manchester Police in 2011/12.

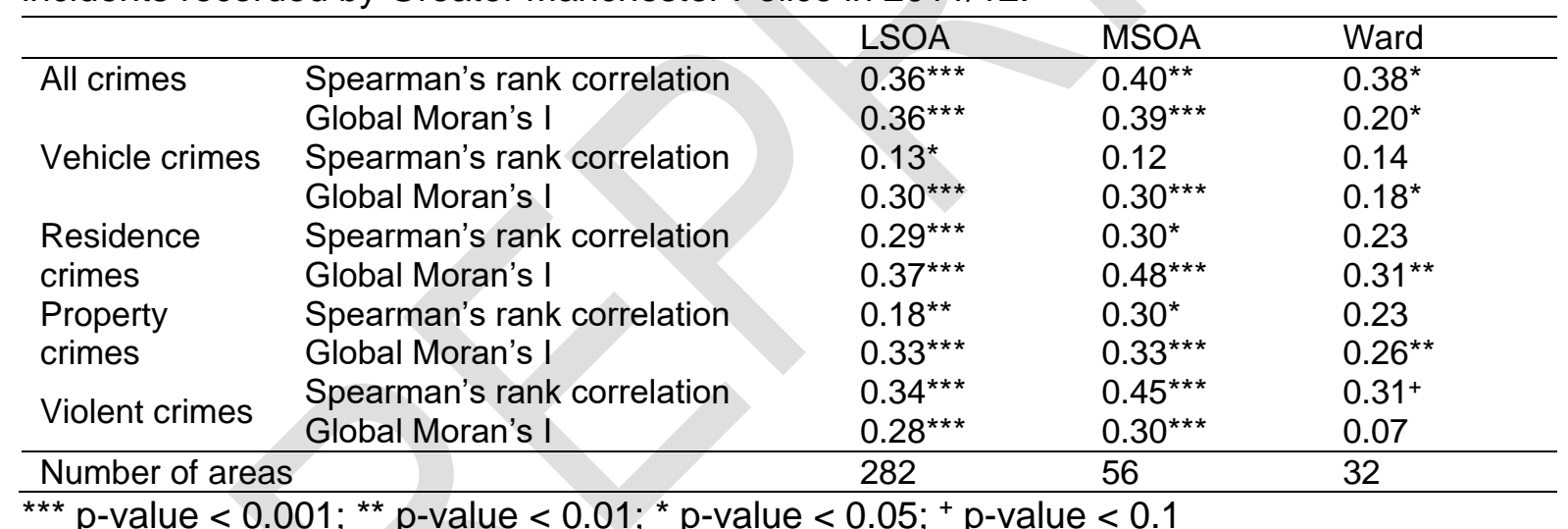

Table 6 shows positive and statistically significant coefficients of Spearman's rank correlation for all crime types at the LSOA level. The index of Global Moran's I is also statistically significant and positive in all cases. At the MSOA level, the coefficient of Spearman's correlation for vehicle crimes is not statistically significant, and at the ward level this coefficient is not statistically significant in several cases. This is likely to be explained by the small number of MSOAs and wards under study (56 and 32, respectively). Generally speaking, our simulated dataset of synthetic crimes is a good indicator of crimes known to police, although both datasets are not perfectly aligned. Our synthetic dataset of crimes may underestimate crimes known to police in areas with a large difference between workday and residential populations, but it appears to be a precise indicator of crimes known to police in residential areas. In the discussion section we present some thoughts about how to address this in future research. 


\subsection{Assessing the results}

In order to assess the extent to which the number of simulated crimes known to police vary from all simulated crimes at the different spatial scales, we calculate the absolute percentage Relative Difference (RD) and the Relative Bias (RB) between these two values for each crime type in each area at four spatial scales.

First, RD is calculated for every area $d$ in the specified level of geography (i.e., Geo $=$ $\{O A, L S O A, M S O A, w a r d s\})$, as follows:

$$
R D_{d}^{G e o}=\left|\frac{E_{d}-K_{d}}{E_{d}}\right| \times 100,
$$

where $E_{d}$ denotes the count of all crimes in area $d$ and $K_{d}$ is the count of crimes known to police in the same area.

Second, RB is computed as follows:

$$
R B_{d}^{G e o}=\left(\frac{E_{d}}{K_{d}}-1\right) \times 100 .
$$

We evaluate the average RD and RB at the different spatial scales, but also their spread, to establish if the measures of dispersion across areas become larger when the geographic scale becomes smaller. This permits a demonstration not just of the mean differences between all crimes and crimes known to police at different spatial scales, but also the variability in these differences, to help shed light on whether there is higher variability at fine-grained spatial scales. This is investigated via the standard deviation (SD), minimum, maximum and mean of the $\mathrm{RD}$ and $\mathrm{RB}$ at the different scales. In addition, boxplots and maps are shown to visualise outputs.

\section{Mapping the bias of police-recorded crimes}

This section presents the results of the simulation study. More specifically, we analyse the mean, minimum, maximum and SD of the RD and RB between all simulated crimes and those synthetic crimes known to the police. We present analyses at the levels of OAs, LSOAs, MSOAs and wards for four different crime types, in order to establish if the variability of the $\mathrm{RD}$ and $\mathrm{RB}$ becomes larger at more fine-grained spatial scales.

First, Table 7 presents the summary statistics of RD and RB for all crime types across the four spatial scales. On average, the RD is close to $62 \%$ at all the spatial scales (i.e., on average, $62 \%$ of crimes are unknown to police at each spatial scale), but the measures of dispersion and the minimum and maximum values - vary considerably depending on the spatial level under study. The SD of the RD between all crimes and police-recorded offences is the largest at the level of OAs, whereas it is much smaller when crimes are aggregated at the LSOA level. It becomes almost zero at the level of MSOAs and wards. In other words, the RD has a large variability across small areas, but it is minimal when using larger geographies. In one OA, the police might be aware of the vast majority of crimes, and in another, very few. Thus, maps produced solely from police records at highly localised spatial scales, such as OAs, may show high concentrations of crime in some areas, but simply as an artefact of the variability in the 
crimes known to police. By contrast, the police know roughly the same proportion of crimes in all MSOAs and wards, with little variation around the mean. This is also observed in the minimum and maximum values. As such, maps of police records produced at these larger scales will reduce the risk of mistakenly classifying some areas as high-crime-density, but not others.

Similarly, the mean RB between all crimes and crimes known to police is roughly the same across all spatial scales, but the SD of the RB varies across levels of analysis. The RD is very large when crimes are aggregated at the level of OAs compared to larger scales.

Table 7. Measures of absolute Relative Difference (RD\%) and absolute Relative Bias (RB\%) between crimes known to police and all crimes (simulated dataset).

\begin{tabular}{llllll}
\hline & & OA & LSOA & MSOA & Ward \\
\hline & Mean & 62.0 & 61.9 & 61.9 & 61.9 \\
$\mathrm{RD} \%$ & SD & 3.5 & 1.4 & 0.7 & 0.6 \\
& Min & 50.4 & 57.5 & 60.7 & 61.0 \\
& Max & 76.3 & 66.5 & 63.9 & 62.8 \\
& Mean & 165 & 163 & 163 & 163 \\
$\mathrm{RB} \%$ & SD & 25.7 & 9.6 & 4.8 & 3.8 \\
& Min & 101 & 135 & 154 & 156 \\
& Max & 322 & 198 & 177 & 169 \\
\hline
\end{tabular}

Results shown in Table 7, nevertheless, are produced from all crime types merged together, and thus are likely to hide important heterogeneity depending on each type of crime under study. Crime research shows that different crime types are affected by different individual and contextual predictors (Andresen and Linning, 2012), and there also differences in terms of crime reporting to the police (Tarling and Morris, 2010). Therefore, some crime types may be less affected by data biases than others, and it may be beneficial to disaggregate results by crime type in order to observe differences that may otherwise remain hidden.

Figure 1 shows boxplots of the RD between all crimes (known and unknown to police) and police-recorded crimes across crime types and spatial scales. Detailed results on this are also shown in the Appendix. We observe that, on average, the RD is lower for violent crimes than any other crime type. Thus, the proportion of total crime known to police is generally larger in the case of violent crimes. We also see that the measures of dispersion in the RD are much larger in the case of property crimes than all other crime types, while the variance of the RD of residence crimes appears to be the smallest. In the case of property crimes and thefts, for example, we observe that there is one $\mathrm{OA}$ with a RD equal to zero and another area with a $\mathrm{RD}$ equal to 100 . In other words, in one OA all property crimes were known to the police, while in the other small area not a single crime was known to police forces. Regardless of the crime type, larger levels of geography are associated with a smaller variance in the RD between areas, whereas the difference between the RD of crime aggregates for MSOAs or wards is generally small. In summary, maps produced from police records at larger spatial scales may show a more valid representation of the geographic distribution of crimes (known and unknown to police) than maps produced for small areas. 


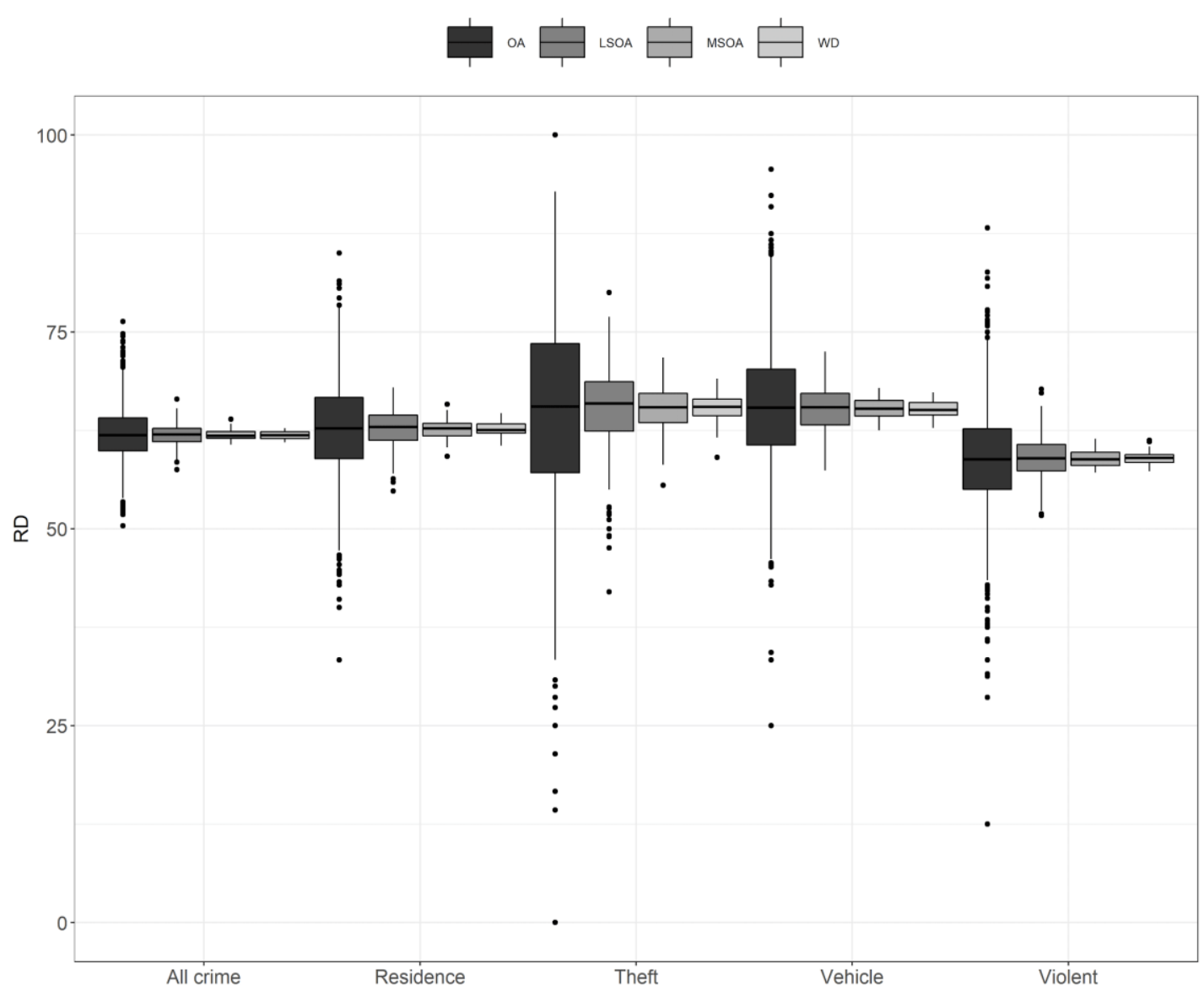

Figure 1. Boxplots of RD\% between all crimes and crimes known to police at the different spatial scales (simulated dataset).

In order to better illustrate the impact of selection bias on maps produced at the different spatial scales, Figure 2 visualises the values of RD between all property crimes and property crimes known to the police at the level of OAs, LSOAs, MSOAs and wards in Manchester. We produce maps of property crimes since it is the crime type with the most extreme measures of dispersion in terms of RD, but similar - less extreme - results are also observed for other crime types. Figure 2 shows that the RD varies widely across OAs (i.e., in some areas no crimes are known to police and in others nearly every crime is known to the police), while the RD between all crimes and police-recorded crimes becomes very homogeneous when crimes are aggregated at the scales of MSOAs and wards. 

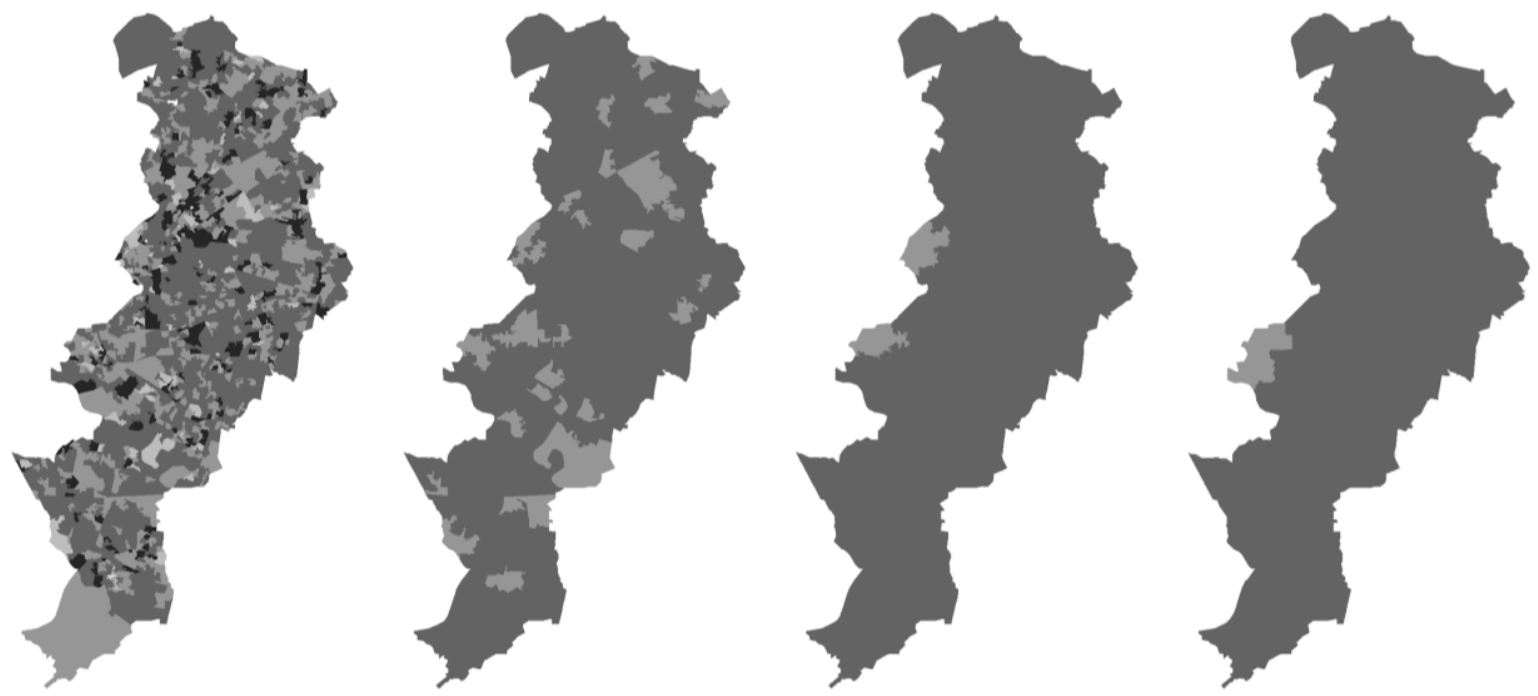

RD \% $\quad 0-20 \quad 20-40$

$40-60$

$60-80$

$80-100$

Figure 2. Maps of RD\% between all property crimes and property crimes known to police at the different spatial scales (simulated dataset). Breaks based on equal intervals.

\section{Discussion and conclusions}

Crime analysis and crime mapping researchers are moving towards increasingly fine-grained geographic resolutions to study the urban crime problem and to design spatially-targeted policing strategies (Braga et al., 2018; Groff et al., 2010; Kirkpatrick, 2017; Weisburd et al., 2012). Nevertheless, aggregating crimes known to police at such detailed levels of analysis increases the risk that the data biases inherent in police records reduce the accuracy of research outputs. These biases may contribute to the misallocation of police resources, and ultimately have an impact on the lives of those who reside in places mistakenly defined as high-crime-density or low-crime-density areas (Skogan, 1977).

This issue around the bias of police-recorded crime data largely depends on residents' willingness to report crimes to police, and the police capacity to control places. Both are known to be affected by social and contextual conditions that are more prevalent in some areas than others (Berg et al., 2013; Goudriaan et al., 2006; Jackson et al., 2013; Slocum et al., 2010; Xie and Lauritsen, 2012). The demographic and social characteristics of micro places are usually very homogeneous (Brattbakk, 2014; Oberwittler and Wikström, 2009), which means that populations unwilling to report crime and cooperate with the police will concentrate in particular places, while other areas may contain social groups that are much more inclined to report crime and work with the police. The influence of these factors is reduced when crimes are aggregated to meso and macro levels of spatial analysis with more heterogeneous populations. Our simulation study shows that maps of police-recorded crimes produced for neighbourhoods and wards show a much more accurate - less biased - image of the geography of crime than maps of crime produced for small areas. This study also 
demonstrates that some crime types are affected by data bias differently, which shows the need to disaggregate analyses by crime types (Andresen and Linning, 2012).

However, our simulation study is also affected by some limitations that could be addressed in future research. Namely, our simulated dataset of crimes captures area victimisation rates instead of area crime rates and, as a consequence, the empirical evaluation when comparing synthetically-generated crimes with actual crimes known to GMP showed that our synthetic dataset could be further improved in those areas with a large difference between workday and residential populations. In order to mitigate against this shortcoming, future research should investigate replicating this analysis using Census data for workday populations instead of Census data for residential populations. This may allow for the generation of more accurate crime counts, especially in non-residential places where crime is prevalent, such as the city centre and commercial districts. There are two further limitations that may have more difficult solutions: (a) the CSEW and most victimisation surveys do not record information of so-called victimless crimes (e.g., drug-related offences, corporate crimes) and homicides, for which generating synthetic estimates may be more complicated; (b) the Census is only conducted every ten years and generating periodic synthetic populations to estimate crime will require the implementation of novel techniques (e.g., spatial microsimulation models; Morris and Clark, 2017).

Those who advocate the use of micro-level crime mapping have well-sustained arguments to claim that mapping crimes at fine-grained levels of spatial analysis allows for better explanations of crime, and more targeted operational policing practices. To mention only a few of their arguments, Oberwittler and Wikström (2009) show that between-neighbourhood crime variance and the statistical power of research outputs increase when smaller units of analysis are used; Steenbeek and Weisburd (2016) show that most spatial and temporal variability in crimes known to police can be attributed to micro-scales, while the variability observed across larger spatial levels is smaller; Braga et al. (2018) show that increasing police control in high-crime-density areas reduces the overall prevalence and incidence of crimes; and Weisburd et al. (2012) argue that the social systems relevant to understanding the crime problem concentrate in small units of geography.

It is not our intention to dismiss the merits of micro-level crime mapping, nor do we directly assess whether the claims made by the advocates of micro-level mapping remain verifiable when analysing unbiased datasets of crime (this is, perhaps, an area for future research). That said, the results reported in this paper serve to raise awareness about an important shortcoming of micro-level mapping. There is a clear need for academics and police administrations to evaluate whether crime rates are associated with conditions external to victimisation. In particular, there is a need to make this evaluation with consideration for the spatial scale being used. The potential sources of bias in police-recorded crime data should always be investigated and acknowledged with this in mind. Further efforts might focus on developing techniques which mitigate against these sources of bias to ensure that crime maps remain an effective tool in understanding and tackling the crime problem. 


\section{References}

Aebi, M. F., and Linde, A. (2012) Conviction statistics as an indicator of crime trends in Europe from 1990 to 2006. Eur J Crim Policy Re, 18, 103-144.

Andresen, M. A., and Linning, S. J. (2012) The (in)appropriateness of aggregating across crime types. Appl Geogr, 35(1-2), 275-282.

Baumer, E. P., and Lauritsen, J. L. (2010) Reporting crime to the police, 1973-2005: A multivariate analysis of long-term trends in the National Crime Survey (NCS) and National Crime Victimization Survey (NCVS). Criminology, 48(1), 131-185.

Berg, M. T., Slocum, L. A., and Loeber, R. (2013) Illegal behaviour, neighborhood context, and police reporting by victims of violence. J Res Crime Delinq, 50(1), 75-103.

Bivand, R., Müller, W. G., and Reder, M. (2009) Power calculations for global and local Moran's I. Comput Stat Data Anal, 53(8), 2859-2872.

Bottoms, A. E., Mawby, R. I., and Walker, M. A. (1987) A localised crime survey in contrasting areas of a city. Brit J Criminol, 23(2), 125-154.

Bowers K., and Johnson, S. D. (2014) Crime mapping as a tool for security and crime prevention. In The Handbook of Security (ed M. Gill), 2nd edition, pp. 566-587. London: Palgrave Macmillan.

Braga, A. A., Weisburd, D., and Turchan, B. (2018) Focused deterrence strategies and crime control: An updated systematic review and meta-analysis of the empirical evidence. Criminol Public Policy, 17(1), 205-250.

Brantingham, P. J. (2018) The logic of data bias and its impact on place-based predictive policing. Ohio St J Crim L, 15(2), 473-486.

Brantingham, P. L., and Brantingham, P. J. (1995) Criminality of place. Crime generators and crime attractors. Eur J Crim Pol Res, 3, 5-26.

Brantingham, P. L., and Brantingham, P. J. (2004) Computer simulation as a tool for environmental criminologists. Secur J, 17, 21-30.

Brattbakk, I. (2014) Block, neighbourhood or district? The importance of geographical scale for area effects on educational attainment. Geogr Ann B, 96(2), 109-125.

Britt, C. L., Rocque, M., and Zimmerman, G. M. (2018) The analysis of bounded count data in criminology. J Quant Criminol, 34, 591-607.

Bruinsma, G. J. N., and Johnson, S. D. (eds.) (2018) The Oxford handbook of environmental criminology. New York: Oxford University Press.

Buil-Gil, D., Medina, J., and Shlomo, N. (2020) Measuring the dark figure of crime in geographic areas. Small area estimation from the Crime Survey for England and Wales. Manuscript submitted for publication.

Chaiken, J. M., and Rolph, J. E. (1981) Methods for estimating crime rates of individuals. The Rand Corporation. Report R-2730//1-NIJ. (Available from https://www.rand.org/content/dam/rand/pubs/reports/2009/R2730.1.pdf).

de Candolle, A. (1830 [1987a]). Considérations sur la statistique des délits. Deviance Soc, 11(4), 352-355. 
de Candolle, A. (1832 [1987b]). De la statistique criminelle. Deviance Soc, 11(4), 356-363.

Goudriaan, H., Wittebrood, K., and Nieuwbeerta, P. (2006) Neighbourhood characteristics and reporting crime: Effects of social cohesion, confidence in police effectiveness and socioeconomic disadvantage. Brit J Criminol, 46(4), 719-742.

Groff, E. R., Weisburd, D., and Yang, S. M. (2010) Is it important to examine crime trends at a local "micro" level?: A longitudinal analysis of street to street variability in crime trajectories. J Quant Criminol, 26, 7-32.

Hart, T. C., and Rennison, C. (2003) Reporting crime to the police, 1992-2000. Special Report. Bureau of Justice Statistics.

HMIC. (2014) Crime-recording: Making the victim count. The final report of an inspection of crime data integrity in police forces in England and Wales. HMIC Report. (Available from https://www.justiceinspectorates.gov.uk/hmicfrs/wp-content/uploads/crime-recording-makingthe-victim-count.pdf).

Jackson, J., Bradford, B., Stanko, B., and Hohl, K. (2013) Just authority? Trust in the police in England and Wales. Abingdon: Routledge.

Kirkpatrick, K. (2017) It's not the algorithm, it's the data. Comm ACM, 60(2), 21-23.

Kitsuse, J. I., and Cicourel, A. V. (1963) A note on the uses of official statistics. Soc Probl, 11(2), 131-139.

Lee, Y., Eck, J. E., O, S., and Martinez, N. N. (2017) How concentrated is crime at places? A systematic review from 1970 to 2015. Crime Sci, 6(6).

Maguire, M., and McVie, S. (2017) Crime data and criminal statistics: A critical reflection. In The Oxford Handbook of Criminology (eds A. Liebling, S. Maruna and L. McAra), 6th edition, ch. 7, pp. 163-189. Oxford: Oxford University Press.

Manchester City Council. (2011). Workday population summary: 2011 census. Manchester City Council Report. (Available from https://www.manchester.gov.uk/download/downloads/id/25545/q05q 2011 census summar y - workday population.pdf).

McCandless, R., Feist, A., Allan, J., and Morgan, N. (2016) Do initiatives involving substantial increases in stop and search reduce crime? Assessing the impact of Operation BLUNT 2. Home Office Report. (Available from https://assets.publishing.service.gov.uk/government/uploads/system/uploads/attachment da ta/file/508661/stop-search-operation-blunt-2.pdf).

Moretti, A. (2020) Simulation studies. In SAGE research methods foundations (eds P. A. Atkinson, S. Delamont, A. Cernat, R. A. Williams and J. W. Sakshaug). SAGE.

Morris, M. A., and Clark, S. (2017) A big data application of spatial microsimulation for neighborhoods in England and Wales. In Big data for regional science (eds. L. A. Schintler and Z. Chen), ch. 20. London: Routledge.

Oberwittler, D., and Wikström, P. O. H. (2009) Why small is better: Advancing the study of the role of behavioral contexts in crime causation. In Putting crime in its place: Units of analysis in geographic criminology (eds D. Weisburd, W. Bernasco and G. J. N. Bruinsma), ch. 2, pp. 3560. New York: Springer. 
Office for National Statistics. (2013) Crime Survey for England and Wales, 2011-2012. [data collection]. (Available from http://doi.org/10.5255/UKDA-SN-7252-2).

Office for National Statistics. (2019) Recorded crime data at Community Safety Partnership and local authority level. [data collection]. (Available from https://www.ons.gov.uk/peoplepopulationandcommunity/crimeandjustice/datasets/recordedcr imedataatcommunitysafetypartnershiplocalauthoritylevel).

Office for National Statistics (2020) Crime Severity Score (experimental statistics). [data collection]. (Available from https://www.ons.gov.uk/peoplepopulationandcommunity/crimeandjustice/datasets/crimeseve rityscoreexperimentalstatistics).

Pebesma, E. (2018) Simple features for R: standardized support for spatial vector data. $R \mathrm{~J}$, 10(1), 439-446.

Pierce, G. L., Spaar, S., and Briggs, L. R. (1988) The character of police work: Strategic and tactical implications. Boston: Northeastern University.

R Core Team. (2017) R: A language and environment for statistical computing. R Foundation for Statistical Computing, Vienna, Austria. (Available from https://www.R-project.org/).

Schnebly, S. (2008) The influence of community-oriented policing on crime-reporting behaviour. Justice Q, 25(2), 223-251.

Sellin, T. (1931) The basis of a crime index. J Crim Law Crim, 22(3), 335-356.

Sherman, L. W., Gartin, P. R., and Buerger, M. E. (1989) Hot spots of predatory crime: Routine activities and the criminology of place. Criminology, 27(1), 27-55.

Skogan, W. S. (1974) The validity of official crime statistics: An empirical investigation. Soc Sci Quart, 55, 25-38.

Skogan, W. G. (1977) Dimensions of the dark figure of unreported crime. Crime Delinquency, 23(1), 41-50.

Slocum, L. A., Taylor, T. J., Brick, B. T., and Esbensen, F. A. (2010) Neighborhood structural characteristics, individual-level attitudes, and youths' crime reporting intentions. Criminology, 48(4), 1063-1100.

Steenbeek, W., and Weisburd, D. (2016) Where the action is in crime? An examination of variability of crime across different spatial units in The Hague, 2001-2009. J Quant Criminol, 32, 449-469.

Tarling, R., and Morris, K. (2010) Reporting crime to the police. Brit J Criminol, 50(3), 474490.

Tiefelsdorf, M. (2000) Modelling spatial processes. The identification and analysis of spatial relationships in regression residuals by means of Moran's I. Berlin: Springer.

Tompson, L., Johnson, S., Ashby, M., Perkins, C., and Edwards, P. (2015) UK open source crime data: accuracy and possibilities for research. Cartogr Geogr Inf Sc, 42(2), 97-111.

UK Statistics Authority. (2014) Assessment of compliance with the code of practice for official statistics. Statistics on crime in England and Wales. Assessment Report 268. (Available from https://www.statisticsauthority.gov.uk/wp-content/uploads/2015/12/imagesassessmentreport268statisticsoncrimeinenglandandwale tcm97-43508-1.pdf). 
von Hofer, H. (2000) Crime statistics as constructs: The case of Swedish rape statistics. Eur J Crim Pol Res, 8, 77-89.

Walker, M. A. (1983) Some problems in interpreting statistics relating to crime. J R Statist Soc A, 146(3), 281-193.

Weisburd, D. (2015) The law of crime concentration and the criminology of place. Criminology, 53(2), 133-157.

Weisburd, D., Bruinsma, G. J. N. and Bernasco. W. (2009) Units of analysis in geographic criminology: Historical development, critical issues, and open questions. In Putting crime in its place: Units of analysis in geographic criminology (eds D. Weisburd, W. Bernasco and G. J. N. Bruinsma), ch. 1, pp. 3-34. New York: Springer.

Weisburd, D., Groff, E. R., and Yang, S. M. (2012) The criminology of place. Street segments and our understanding of the crime problem. New York: Oxford University Place.

Weisburd, D., and Lum, C. (2005) The diffusion of computerized crime mapping in policing: Linking research and practice. Police Pract Res, 6(5), 419-434.

Xie, M. (2014) Area differences and time trends in crime reporting: Comparing New York with other metropolitan areas. Justice Q, 31(1), 43-73.

Xie, M., and Lauritsen, J. (2012) Racial context and crime reporting: A test of Black's stratification hypothesis. J Quant Criminol, 28, 265-293. 


\section{Appendix}

$\mathrm{RD} \%$ between all crimes and crime known to police by spatial scale and crime type (simulated dataset).

\begin{tabular}{llllll}
\hline & & OA & LSOA & MSOA & Ward \\
\hline \multirow{2}{*}{ Vehicle crimes } & Mean & 65.3 & 65.2 & 65.2 & 65.2 \\
& SD & 7.6 & 3.0 & 1.5 & 1.2 \\
& Min & 25.0 & 57.5 & 62.5 & 62.8 \\
\multirow{5}{*}{ Residence } & Max & 95.7 & 72.5 & 67.9 & 67.3 \\
crimes & Mean & 62.7 & 62.7 & 62.7 & 62.7 \\
& SD & 6.2 & 2.5 & 1.3 & 0.9 \\
\multirow{5}{*}{ Property } & Min & 33.3 & 54.8 & 59.2 & 60.6 \\
crimes & Max & 85.0 & 67.9 & 65.8 & 64.7 \\
& Mean & 65.0 & 65.1 & 65.3 & 65.2 \\
& SD & 13.4 & 5.5 & 3.0 & 2.0 \\
\multirow{5}{*}{ Violent crimes } & Min & 0.0 & 42.0 & 55.5 & 59.1 \\
& Max & 100.0 & 80.0 & 71.7 & 69.1 \\
& Mean & 58.7 & 59.0 & 59.0 & 59.0 \\
& SD & 6.7 & 2.5 & 1.2 & 0.9 \\
& Min & 12.5 & 51.7 & 57.1 & 57.3 \\
& Max & 88.2 & 67.7 & 61.4 & 61.3 \\
\hline
\end{tabular}

